\title{
واقع ممارسة القيادة المستلاملة فى ملارس التعليم الثانوى العام بمحافظات جنوب صعيد مصر من وجهة نظر المعلمين والمديرين.
}

\section{اعداد}

\section{أ.م. د/ محمل صبري الأنصاري}

أستاذ التربية المقارنة والإدارة التعليمية

كلية التربية بقتا- جامعة جنوب الو ادي لئرية

\section{م.م/ منال محمدل بكرى حسن}

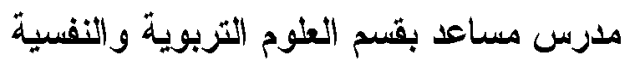

كلية التزبية النوعية بقتا- جامعة جنوب الوادي لئي

\section{أ.د / أشرف محمود أحمد}

أستاذ التربية المقارنة والإدارة التعليمية

كلية التربية بالغردقة - جامعة جنوب التوادي

د د صابريز نشأت عبدالرازق

مدرس التربية المقارنة والإدارة التعليمية كلية التربية بقنا- جامعة جنوب الوادئ الدئ 
واقع ممارسة القيادة المستدامة فى مدارس التعليم الثانوى العام بمحافظات جنوب صعيد مصر من وجهة نظر المعلمين والملديرين.

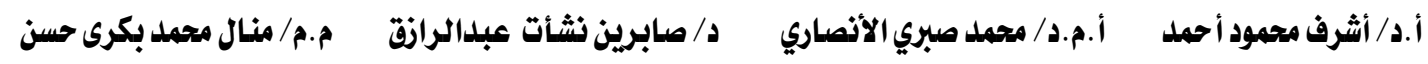

واقع ممارسة القيادة المستلدامة فى ملارس التعليم الثاذوى العام بمحافظات جنوب

صعيد مصر من وجهة نظر المعلمين والملديرين.

اعداد

\section{أ.م. دأم محمد صبري الأنصاري}

أستاذ التربية المقارنة والإدارة التعليمية

كلية التربية بقنا- جامعة جنوب الو ادي التئي

م م م منال محمدل بكرى حسن

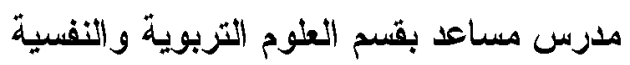
كلية التزبية النوعية بقتا- جامعة جنوب الو ادي لئي

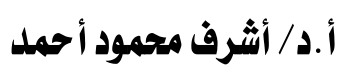

أستاذ التربية المقارنة و الإدارة التعليمية كلية التربية بالغردقة - جامعة جنوب الوادي التئية

\section{د د صابرين نشأت عبدالرازق}

مدرس التربية المقارنة والإدارة التعليمية

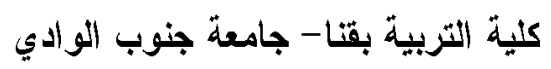
المستخلص:

هدف البحث الحالى إلى التعرف على واقع ممارسة القيادة المستدامة فى مدارس التعليم الثانوى العام بمحافظات جنوب صعيد مصر من وجهة نظر المعلمين و المديرين، ولتحقيق هدف البحث نم الاعثماد على المنهج الوصفى بصفتة المنهج الأكثر ملائمة لطبيعة الدراسة، وثم الاعتماد على الاستبانة كأداة لجمع البيانات، حيث ثم بناء استبانة نكونت من خمسة أبعاد هى (التعلم العميق - تتمية وتحسين الموارد البشرية والمادية - ثنىى الرؤية طويلة الأمد - ثبنى ورعاية الابنكار والابداع السلوك الأخلاقي)، وبلغت عينة الدراسة ( . ب) من المديرين والمعلمين بإدارات محافظات (سوهاج - ثنا - الأثصر)، وثم تثريع الييانات ومعالجنها إحصائباً، وتوصلت نتائج البحث إلى أن ممارسة القيادة المستثامة كانت "مثوسطة"، وقدمت الدراسة بعض التوصبات لتفعيل نطبيق القيادة المستدامة بمدارس التعليم الثانوى العام. الكلمات المفتاحية: القيادة المسندامة - مدارس الثعليم الثانوى • 


\section{واقع ممارسة القيادة المستدامة في مدارس التعليم الثانوى العام بمحافظات جنوب صعيد مصر من وجهة نظر المعلمين والمديرين.

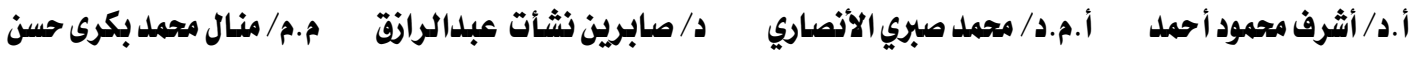

\section{The Reality Of sustainable leadership practice In General Secondary Schools in the Governorates of Southern Upper Egypt from the Viewpoint of Teachers and Principals.}

Prof.Dr.:Ashraf Mahmoud Ahmed

Prof. Comparative Education ,

Educational Management

Faculty of Education in Hurghada

South Valley University

Dr.:Sabren Nashat Abdelraziq

Comparative Education and Educational

Management Teacher

Faculty of Education of Qana

South Valley University

\section{Prepared by}

\section{Abstract:}

The current research aimed to identify the reality of the sustainable leadership practice in general secondary schools in the governorates of southern Upper Egypt from the point view of teachers and principals. To achieve the goal of the research, the descriptive approach was relied on as the most appropriate approach to the nature of the study, and the questionnaire was relied on as a data collection tool. a questionnaire consisting five dimensions (deep learning - developing and improving human and material resources - adopting a long-term vision - adopting and nurturing innovation and creativity - ethical behavior). The study sample amounted to (600) principals and teachers in the administrations of the governorates (Sohag - Qena - Luxor), and the data were subdivided and processed statistically. The results of the research concluded that the practice of sustainable leadership was "medium", and the study made some recommendations to activate the application of sustainable leadership in public secondary schools.

Key words: sustainable leadership - Secondary education schools.

العلد الثامن والأربعوز


تعد القيادة الثربوية بمثابة العمود الققرى فى أى مؤسسة تعليمية، وهى المسئولة عن تحقيق التكامل و التنسيق بين كافة دذخلات العملية التعليمية، كما تعمل على مساعدة المؤسسات التعليمبة فى تحقيق الأهداف التى حددها المجتمع، و التى قد نكون متعلقة بالطلاب أو بييئة التعلم أو المجنمع وتحقيق منطلباته؛ حيث ثساهم القيادة التربوية فى بناء مجنمع بسير وفقاً للتنمية المستذامة. وقد زاد الاهنمام فى الآونة الاخيرة في مجال القيادة بالتركيز على ثبنى الرؤى المثمركزة حول الأفراد والموارد، وظهرت الدعوة إلى نبنى مداخل قيادية ذات دمارسات أكثر بقاءاً، وذلك نتيجة للتضخم الاقتصادى الذى دعا المؤسسات المختلفة إلى البحث عن نمو آمن ومسثقر بالاعتماد على المداخل القبادية التى ثهثم بالأهدات والممارسات طويلة الامد، مما بساعد هذه المؤسسات على النمو فى بيئة تتسم بقر كافى من الاسندامة لكى نكون لابها القدرة على مواجهة التحديات الخارجية من حولها(McCann \& Sweet, 2014, p. 374). ويعد نمط القيادة المستدامة من الأنماط القبادية الحديثة التى ثركز على الحفاظ على الموارد فى المؤسسات التعليمية سواء كانت موارد بشربة أو مادية، والعمل على استغلالها وعدم استنزافها من خلال تذليل العقبات الثى تحول دون ديمويمة واستقرار المؤسسات التعليمية واستداهتها، بالإضافة إلى عمل تغييرات ذات معنى نساعد المؤسسة والعاملين بها على تحقيث أهدافها بصورة أكثر فاعلية من خلال تطبيق ممارسات القيادة المستدامة.

وتكمن أهمية القيادة المستدامة في الميدان التربوي في أنها ضرورية للحفاظ على الثقافة المدرسية الإيجايية ، والروح المعنوية العالية بين أعضاء المجتمع 
المدرسي ، كما نعمل على مثاركة أعضاء المجنمع المدرسي في وضع رؤية المدرسة ورسالتها ، كما أنها عامل هام وأساسي للنمو الأكاديمي للطلاب وكذلك النمو ، المهني للمعلمين (13 -12 12) ؛ حيث أنها نمط قيادي بنتشر ويستمر بين الأفراد ويدوم عبر الزمن ، بحبث أنها مسئولية مشتركة بين القائمين على

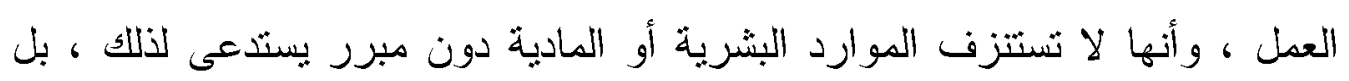
تهنم وتبتعد عن إلحاق الضرر السلبى بالبيئة التعليمية والمجتمع المحيط ، من خلال ارتباطها الفعال مع القوى التي تؤثر بها ، وبناء بيئة تعليمية للتتوع المنظم الذى يؤدى إلى انتاج الأفكار الجيدة ، والممارسات الناجحة في مجنمعات الثعلم والتطور

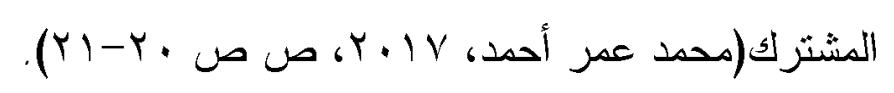

كما ثتألف القيادة المستدامة من مجموعة من المبادئ التى ثتو افق مع ما يهدف

إليه القائد الناجح فى الارثقاء بمؤسسته وتحسين أداء العاملين بها ، واسثثار الموارد المتاحة بالثكل المطلوب ، وبما يضمن بيئة مناسبة للعمل في الحاضر و المسثقبل ومن هذه المبادئ أن القيادة المستدامة مستمرة فهي تنطوي على التخطيط وإعداد القادة للمر احل المستقبلية من خلال قيام القائد بالاهنمام بالأفر اد الناجحين و المنميزين و الذين يملكون مهارات وشخصيات القادة لإعدادهم للمرحلة المستقبلية، كما أنها عادلة اجثماعياً حبث ثحرص القبادة المستدامة على نشر العدالة التظظيمية بالمؤسسة التعليمبة ، وتلبية احتباجات أعضاء المجمع المدرسي على حد سواء ، فهي ليست مجرد عملية

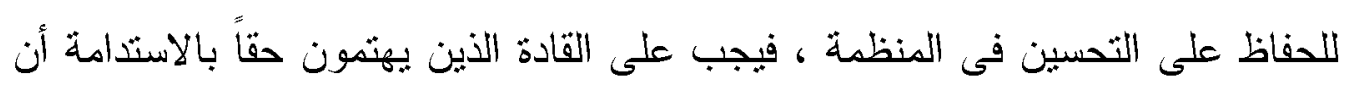
يتحملو مسؤولية المنظمة والموظفين ، وأن يدركوا أن أفعالهم لها ثأثير على بيئهم وليس فقط على الييئة الداخلية للمنظمة ، كما نزعى وتحمى القيادة المستدامة تعلم مستدام وعميق ، فهي تثجاوز تحقيق نتائج تحصيل مؤقته إلى إيجاد تحسينات دائمة فى 
Hargreaves \& Fink, 2005, p.p ) التعلم وليس على تحسين درجات الاختبار .$(251-253$

وللقبادة المستدامة دور فعال فى تهيئة وتطوير المناخ التنظيمي الداخلي للمدرسة الذى يسهم فى نشر ثقافة الإبداع الإداري ، وذللك من خلال أنباع سلوكيات وسمات ومهار ات ثيادية نساعد على النهوض والارتقاء بقدرات الطلاب و الموظفين وتتجعهم على تطوير الملكات الإبداعية والابتكارية لديهم وتؤهلهم لأن بصبحوا قادة فى المستقبل. Suriyankietkaew, 2016, p. 248) وللتعليم الثانوى العام مكانة مهمة فى السلم التعليمى ، ويعمل في إطار سياسة تعليمية عامة ثسعى إلى نتمية المجنمع ، وتحقيق أمنه ليكون مواكباً للتغيرات الحادثة فيه ، الأمر الذى يفرض ضرورة أن تصبح المدرسة الثانوية منظمة تعلم قادرة على

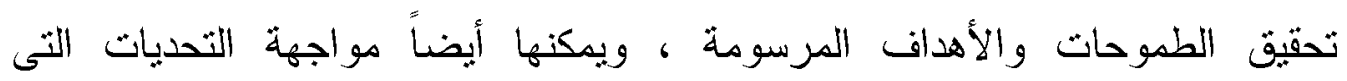
يفرضها عصر المعرفة والثقدم التكنولوجى ، وعليه بمكن القول إن تحقيق أهداف التعليم الثانوى المنشود يأتى من نبنى ثنافة نتظيمية نتسم بالعمل الجماعى ، وتبنى مدخل إدارى يمكن من خلاله تحسين مستوى أداء العاملين بالمدرسة.( أمل محسوب

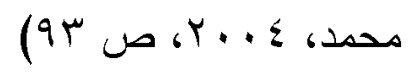

$$
\begin{aligned}
& \text { مشكثة البحث }
\end{aligned}
$$

يعد نمط القبادة المستدامة من الأنماط القيادية التى تصلح لتطبيقها فى أى

بيئة سواء كانت اقتصادية أو تجارية أو تعليمبة، حيث أنها ثركز على الممارسات والتطبيقات التى من شأنها تحقيق الاستدامة، وكذلك تتمية مهارات الكوادر البشري وتتمية الموارد المادية والحث على التعليم والاندماج بصورة مستمرة مع الييئة وتحقيق العدالة بصورة فعالة فى كل جوانب العمل فى المؤسسات التعليمية. 
وهنالك العديد من العوامل التى ثؤثر على المنظمات التعليمية وتطالبها بتبنى ونطبيق القيادة المستدامة مثل ثقنيات المعلومات والاثصالات وتحديات العولمة و السرعة المتزايدة فى عمليات التغيير التربوى، والتوسع الهائل فى التواصل الاجتماعى وشبكاته، وتثيع قاعدة المشاركين والمهتمين بالعملية التحليمية فى المجتمع على المستوى الاجتماعى والاقتصادى واليئى، هذا بجانب نغير احتياجات المتعلمين، و هذا بتطلب من القادة فى هذه المنظمات أن يتصرفو ابثكل اكبر دسئولية من الناحية الاجتماعبة و الافتصادية و البيئية. (Coyne, 2017, p. 4- 5) وبالرغم من أهمية القيادة المستدامة فى الثعليم إلا أن عملية تطيقها ليست علية سهلة وتتطلب ثضافر الجهود بين كلا من القادة والمعلمين والموظفين وطاقم العدل بالمدرسة، كما تتطلب وجود التزام من جميع الاطراف السابقة فى القيام بالمهام المنوطة إليهم مع توسيع دائرة المثناركين فى عملية القيادة.( .(Simanskiene, et al., 2016, p. 658 وقد أهتمت العديد من الدراسات بنمط القيادة المستدامة وعلاقته ببعض

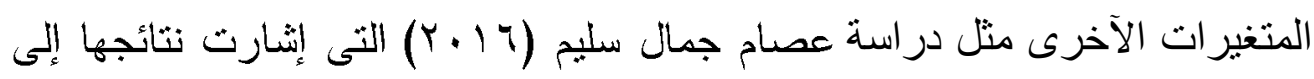
أهمية القيادة المستدامة فى مجال التطوير الجامعى بجمهورية مصر العربية وأن

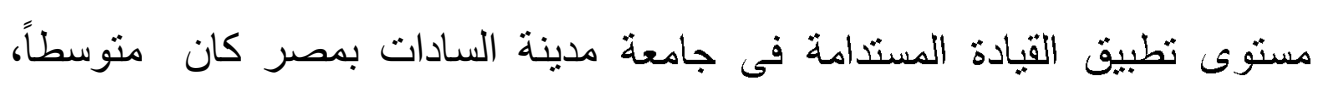

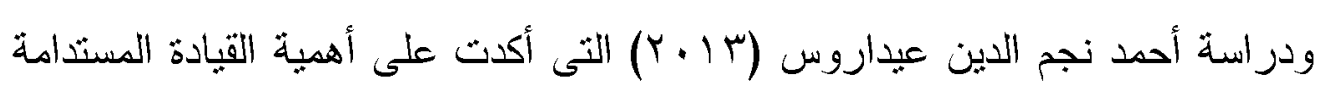
ودور ها فى إرساء نقافة النزاهة التتظيمية بمؤسسات التعليم العام بالسعودية، ودراسة حسين هجبل ، فيصل غلاب(Y V V التى إثارث نتائجها إلى أن درجة اتساق الممارسات القبادية لمديرى المدارس بدولة الكويت مع مبادئ القيادة المستدامة وأكدت إيضا على أهمية القيادة المستدامة وضرورة تدريب مديرى المدارس عليها، ودراسة محمد عمر أحمد (Y.IV) التى أوصت بضرورة عقد دورات ندريبية 
لمدراء المدارس لنتريب على القيادة المستخامة ومن ثم نطبيق مبادئها فى مدارسهم نظر لدورها الكبير فى تطوير الإدارة بوجه عام والإدارة المدرسية بوجه خاص، ودراسة أمانى محمد يونس(Y) V. V) الثى أوصت بممارسة مديرى هدارس وكالة الغوث الدولية لنمط القيادة المستدامة لما له من أثر على جودة الحياة الوظيفية لدى معلميهم، ودراسة Kantabutra \& Saratun (2013) التى هدفت الدراسة إلى الكثنف عن واقع ممارسات القيادة المستدامة فى إحدى الجامعات بنايلاند ، وذلك استتاداً لنموذج "إفرى" و"بريجستتر" وقد بينت النتائج تحقق" آب" هن أصل "بس ب" من ممارسات القيادة المستدامة موزعة على ست مجموعات رئيسية من الممارسات، ودراسة Cook (2014) التى هدفت إلى الكثف عن أهمية القيادة المدرسية المستدامة و الطريقة التى ينظر بها للقيادة المستدامة من قبل المعلمين ، وما هىى العناصر وقد ثوصلت الدراسة إلى أهمية القيادة المستدامة والحاجة إليها من أجل الحفاظ على النمو الأكاديمى للطلاب و النمو المهنى للمعلمين. كما قامت الباحثة بإجراء بعض الزيارات والمقابلات مع بعض مديرى المدارس الثانوية العامة في بعض محافظات جنوب الصعبد ، ونيين من نتائج هذه المقابلات والزيارات انخفاض وعى العديد من المديرين بنمط القبادة المستدامة بالرغم فو ائده العديدة على عمل الإدارة المدرسية بتلاك المدارس ، فبتالي تأنى هذه الدراسة لتلقى الضوء على نمط إدارى وقيادى حديث بساعد فى تطوير وتحسين العملية التعليمبة بوجه عام.

وتعد المدارس بصفتها نمنلك أدوار حيوية وخطيرة فى المجنمع هى الاولى

بتطبيق القيادة المستدامة من خلال اتباع المبادئ الثى نتادى بها القيادة المستدامة ، ونظراً لأهمية هذا النمط من القيادة وماتتادى به الدراسات من اهمبة نطبيقه نسعى 
الدراسة الحالية إلى التعرف على واقع تطبيث ممارسات هذا النوع من القيادة فى مدارس التعليم الثانوى العام فى محافظات جنوب الصعيد بمصر من وجهة نظر المعلمين و المديرين.

وفى ضوء ذلك ثتمثل مثكلة البحث الحالى فى الحاجة إلى التعرف على

و اقع تطبيق القيادة المستدامة فى مدارس التعليم الثانوى العام بمحافظات جنوب

صعيد مصر من وجهة نظر المعلمين و المديرين. أسئلة البحث

يحاول البحث الحالى الاجابة على الاسئلة التالية:

ا- ما الاطار النظرى للقيادة المستدامة فى الادبيات الإدارية والثربوية المعاصرة؟ Y- ما و اقع ممارسة القيادة المستدامة فى مدارس التعليم الثانوى العام بمحافظات

جنوب صعيد مصر من وجهة نظر المعلمين و المديرين؟

س- ما مقترحات ثفعيل تطبيق القيادة المستدامة فى مدارس الثعليم الثانوى العام

بمحافظات جنوب صعيد مصر؟

\section{أهداف البحث}

بسعى البحث الر اهن إلى تحقيق الأهداف الثالية:

ا- الثعرف على الاطار النظرى للقيادة المستدامة فى الادبيات الإدارية والتربوية

المعاصرة.

r- التعرف على و اقع ممارسة القيادة المستدامة فى مدارس التعليم الثانوى العام

بمحافظات جنوب صعبد مصر من وجهة نظر المعلمين والمديرين.

ب- طرح مجموعة من التوصيات التى بمكن أن تسهم فى تفعيل ممارسة القيادة

المستدامة فى مدارس التعليم الثانوى العام بمحافظات جنوب صعيد مصر. 
تتمثل أهمية البحث الحالى فى : الأهمية النظريةة: والمنمثة فى الوصف لمثغير البحث (القيادة المستدامة)، وهى من أنماط القيادة الحديثة التى بوصى بها الفكر الادارى الحديث ويوصى بتنبيها وتطيبقها فى المؤسسات بشنى انواعها ومنها المؤسسات التعليمية، وتبرز الاهية من الاثراء الذى قد بسهم فيه البحث من خلال عرض الاطر النظرية والدراسات السابقة التى تنتاول المتغير وثوضح بعض العناصر المتعلقة به. الأهمية التطبيقية: والمتمثلة فى نقديم وصف لواقع تطبيق القيادة المستدامة فى مدارس التعليم الثانوى العالك بمحافظات جنوب صعيد مصر، مع تقديم بعض التوصيات لتفعيل عملية التطبيق والتى بدروها قد نساهم فى تطوير عمليات القيادة المتبعة فى مدارس التعليم الثانوى العام، كما يمكن ان يستقيد مدير المدارس الثانوى العامة من نتائج البحث وكذلك القائمين على عملية التدريب من خلال ثقديم برامج تدريبية لقيادات ومعلمي المدارس الثانوية العامة على مهار ات هذا النمط دن القيادة. محددات البحث

المحدات الموضوعية: اقتصر البحث على الثعرف على واقع نطبيق القيادة المستدامة فى مدارس التعليم الثانوى العام (الحكومية - عربي) بمحافظات جنوب صعيد مصر من وجهة نظر المعلمين والمديرين، دع ثقديم بعض الثوصيات. المحدات البشرية والمكانية: اقتصر البحث عينة من المعلمين والمديرين بمدارس التعليم الثانوى العام الحكومى بمحافطات جنوب صعيد مصر منمثلة فى محافظات (سوهاج - قنا - الاقصر) باعثبار ها المحافظات الاقرب الى محل عمل الباحثة وبلغ

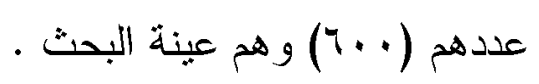




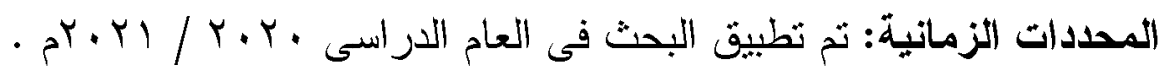

\section{مصطاح البحث}

Sustainable Leadership

القيادة المستـامة

يعرف رافد حمبد الحدراوى و آخرون (1) •. ، ، ص •9 1) القيادة المستدامة

بأنها منظور إدارى جديد بهدف الى تحقيق نتائج منمبزة والمحافظة عليها ونتشجيع حالات الابداع والابنكار فى العمل وثنتى رؤية واضحة وثوجه مستدام طويل الامد. ويعرفها كلا من أمال عبدالمجيد الحيلة ، سامر محد عرثاوى (19 ب r ، ص سهo بأنها القيادة الثى ثركز فى إدارتها على استدامة مواردها المادية والبشرية

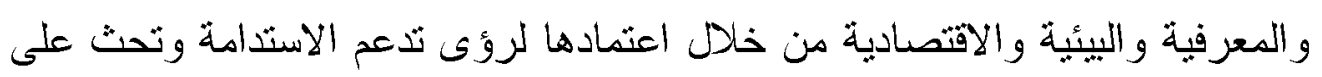
التعلم و الاندماج فى البيئة.

وتعرف إجرائياً فى هذا البحث بأنها :" مجموعة من الممارسات القبادية والإدارية الثى نثبعها إدارة المدرسة الثانوية والثى ثسعى من خلالها إلى تطبيق مدارسات القبادة المستدامة من خلال الابعاد المكونة لها وهى ( التعلم العميق، نتمية وتحسين الموارد البشرية والمادية، تبنى الروية طويل الأمد ، تبنى ورعاية الابتكار والابداع، السلوك الأخلاقى) . الار اسـات السابقة فى القيادة المستدامة

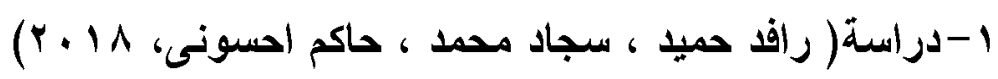
هدفت الدراسة إلى الكثن عن طبيعة القيادة المستدامة وواقع ممارسات إبعادها فى مطار النجف الاتشرف الدولى ، وتأثير ها على التفوق التظيمى ، ولتحقيق أهداف الدراسة استخدم الباحثنون المنهج الوصفى التحليلى الذى بعثد على الاستبانة كأداة لجمع البيانات، وقد نكونت عينة الدراسة (V · r. من الأفر اد الموظفين بالمطار 
، وقد ثوصلت الدراسة إلى أن ثبنى ممارسات القبادة المستدامة في مطار النجف الاشرف الدولى يساعد إدارة المطار فى تحقيق التفوق التنظيمى، كما أثنارت الدراسة إلى أن القيادة المستدامة تعتبر إبرز الأنماط القيادية فى الوقت الحاضر والتى تمنح المنظمة قوة دائمة من خلال تتمية مهار ات كوادرها وجعلهم على درجة عالية من الالتزام بتحقيق أداء مثميز.

$$
\text { r-دراسة عصام محمد على (19 (r) }
$$

هدفت الدراسة إلى تعرف درجة أهمية تطبيث القبادة المستدامة بجامعة الملك خالد فى ضوء نموذج إفرى وبريجستتر، واعتمدث الدراسة على المنهج الوصفى التحليلى، والمنهج البنائى، وبلغت عينة الدراسة ؟ـب عضو هيئة ندريس، وثم الاعنماد على الاستبانة في جمع البيانات، و أثنارت نتائج الاراسة إلى أن اهمية نطبيق القيادة المستدامة فى ضوء نموذج إفرى وبريجستتر مرتفعة، وأوصت الدراسة بأهمية إجر اء دراسات حول القيادة المستدامة وتطبيقها فى مؤسسات الثعليم

المختلفة.

r-دراسة سهير محمد ، نورة المطيرى (19 ب (r)

هدفت الدراسة الى الكثف عن مستوى نطبيق قائدات المدرسة الثانوية

الحكومية بثمال الرياض من وجهة نظر المعلمات، واعتمدت الدراسة على المنهج الوصفى المسحى، واستخدام الاسنبانة أداة الدراسة لجمع الييانات، وبلغت عينة الدراسة AVA معلمة، ونوصلا الدراسة الى أن مسنوى ثطبيق قائداث المدارس الثانوية بشمال مدينة الرياض لاجمالى أبعاد القيادة المستدامة جاء بدرجة منوسطة. كما ثوصلت الدراسة الى ان اهم سبل التحسين لنطبيق أبعاد القبادة المستدامة من وجهة نظر المعلمات هى الاهنمام بالحوافز المادية والتأكبد على اهمية الربط بين 
محتوى النتائج الدراسية وحياة الطالبات لتحقيق أبعاد القيادة المستدامة حيث يؤدى ذلك الى نطوير مهار ات الطالبات تجاه التعلم المستمر ·

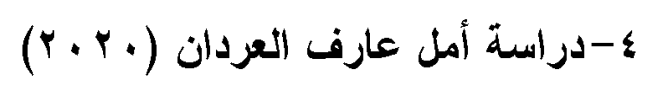

هدفت الدراسة الى تحديد واقع اداء القيادات الاكاديمية فى الجامعات

السعودية الناشئة في ضوء القيادة المستدامة، وثم الاعثماد على استبانة اعضاء هيئة التدريس فى كثف و اقع أداء القيادة المستدامة، واستخدمت الدراسة المنهج الوصفى وتم تطبيق الدراسة على عبنة دن أعضاء هبئة التدريس بثالاث هن الجامعات السعودية الناشئة وبلغ عدد العينة ه اس عضو، وخلصت الدراسة الى ان درجة واقع اداء القيادات الاكاديمبة فى ضوء ابعاد القيادة المستدامة منوسطة.

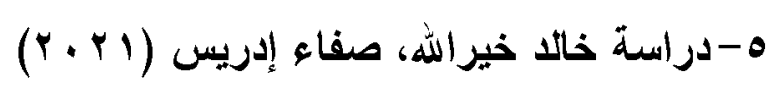

هدفت الدراسة إلى اختبار علاقة تأثثر القيادة المستدامة المثمثة ب (التنوع

المنماسك،العدالة التتظيمية، تطوير العاملين، التوازن ما بين العمل والحياة الخاصة، التوجه نحو الثقدم) في السلوك الإسنباقي، المنثثة ب (صوت الموظف، تحمل المسؤولية، منع وقوع المشاكل، الابتكار الفردي). واستخدمت الاراسة الاسنبانة بوصفها الأداة الأساسية في الحصول على البيانات والمعلومات. وتبنت الدراسة المنهج الوصفي التحليلي بوصفه منهجا مناسبا، وكان استخدامه لتعزيز وتدعيم هذه المفاهيم، وبلغت عينة الدراسة جاس تدريسيا وبمختلف الألقاب العلمية (مدرس مساعد، مدرس، أستاذ مساعد، أستاذ)، وأثنارث نتائج الدراسة الى وجود علاقة ايجابية بين مثغيرات الدراسة واوصت الدراسة بضرورة ثزويد المؤسسات التعليمية بالاطر النظرية و الهيكلية التى تنتاسب ومتطلبات القيادة المستدامة. 


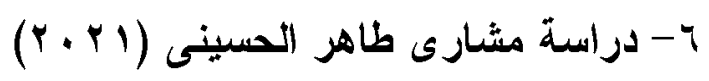

هدفت الاراسة اللى التعرث على واقع ممارسات القيادة المستدامة في

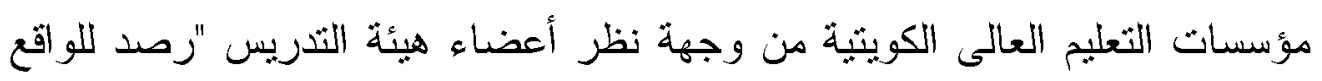

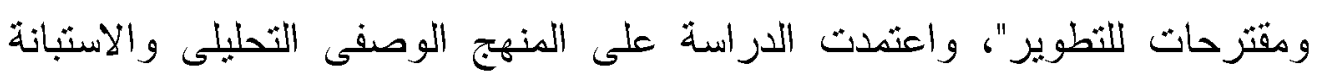

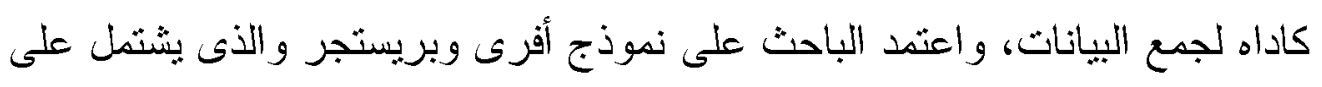
ثلاث مستويات للممارسات فى القبادة المستدامة وهى الممارسات التأسيسية و الممارسات عالية المستوى وحو افز الأداء الرئيسية، وقد جاءت نتائج الدراسة لنتير ونير إلى أن متوسط تطبيق ممارسات القيادة المستدامة من وجهة نظر العضداء العضاء هيئة التذريس كانت منوسطة. McCann \& Holt,2010 دراسة ( هدفت هذه الدراسة إلى تحديد مستويات ممارسات القبادة الخادمة والقيادة المستدامة من وجهة نظر جميع الموظفين فى مجموعه منتقاه من المنظمات الصناعية بالولايات المثحة الأمريكية فضلا عن الكثف عن مدى وجود علاقة ارتباطية بين القيادة الخادمة و القيادة المستدامة ، ولتحقيق أهداف الدراسة استخدم الباحثين المنهج الوصفى المسحى الذى بعثمد على الاستبانة كأداة لجمع الييانات ، وقد نوصلت الدر اسة إلى وجود علاقة دالة بين القيادة الخادمة والقيادة المستدامة.

- א- دراسة (Kantabutra\& Saratun,2013) هدفت الدراسة إلى الكثف عن واقع ممارسات القيادة المستدامة فى إحدى الجامعات بثايلاند ، وذلك استناداً لنموذج "إفرى" و"بريجسنتر" وقد نم نصنيف المبادئ التى قدمها هذان الباحثنان إلى ست فئات رئيسية وهى : المنظور طويل الأمد ، ونظوير طاقم العمل ، و الثقافة التنظيمية ، والإبداع ، و المسؤولية الاجنماعية ، والسلوك الأخلاقى ، وذلك كنموذج لتحليل واقع تطبيق ممارسات القيادة المستدامة 


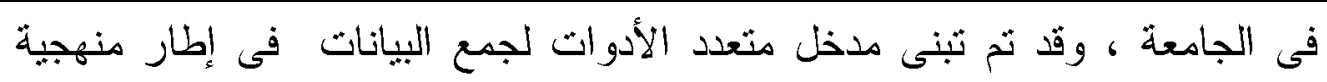
دراسة الحالة ، وذلك باستخدام الملاحظة ، وتحليل الوثائق و المعلومات المثعلقة بالجامعة ، وإجر اء المقابلاث الثخصية شبه المقننة مع العاملين فى الجامعة ، وقد بينت النتائج تحقق" آ" من أصل "بr" من همارسات القبادة المستدامة موزعة على ست مجموعات رئيسية من الممارسات وهى : المنظور طويل الأمد ، وتطوير طاقم العمل ، والثقافة التتظيمية القوية ، و الإبداع ، و المسؤولية الاجتماعبة و الييئية ، و السلوك الأخلاقى.

وباسنعراض الاراسات والبحوث السابقة نجد أن هذا البحث بيثابه مع الدراسات السابقة فى الادوات المستخدمة وفى المنهج المستخدم ويختلف معهم فى النطاق الجغرافى وفى مجتمع الدراسة وفى عدد العينة المستخدمة وفى الابعاد المستخدمة في القيادة المستدامة، وثد استفادت الباحثة من الدراسات السابقة في إعداد ادة الدر اسة وصياغة عبار اتها وفى تحديد المنهية والتصميم البحثى المناسب. الاطار النظرى للقيادة المستدامة مفهوم القيادة المستدامة يعد مفهوم القيادة المستدامة من المفاهيم الحديثة فى مجال الادارة فى المجالات المختلفة، ولهذا تعددث التعريفات التى تتاولت المفهوم بالتوضبح على حسب اختلاف وجهات النظر فى النظر إلى طبيعة المفهوم. وقد ثم ثقديم مفهوم القيادة المستدامة لأول مرة من منظور أن المنظمات لها مساهمة في العالم الطبيعي، ويسلط هذا المنظور الضوء على ضرورة إنشاء قيادة مستدامة من أجل دعم النواحى المادية والاجتماعية والاخلاقية والاقتصادية داخل المنظمات (Shrivastava, 1995, p. 938). 
وتعددت التعريفات التى تتاولت مفهوم القيادة المستدامة حبث اهتمث العديد من الدراسات بوضع تعريف لها، ويعد "هارجريفز" من الرواد فى هذا المجال من خلال كتابة "القبادة المستدامة" الذى وضح فيه تعريف ومبادىء القبادة المستدامة، فقد عرفها بانها "القيادة التى تساهم فى تتمية التعلم العميق بطريقة تؤدى إلى أحداث تأثير ات إيجابية فى كافة المعنين بالامر فى المؤسسات النعليمية فى الوقت الحاضر ومسثقبلانًا (Hargreaves, 2007, p. 224).

ويعرفها البعض بأنها القيادة التى تؤثز بايجابية فى العاملين بالمؤسسة

التعليمية من أجل تحقيق أهداف المؤسسة فى إطار شر اكة مهنية مع كافة العاملين بما بيساهم فى استدامة انجاز المهام والمسئوليات وتحقيق الأهداف النتظيمية للمؤسسة) (Hardie, 2011, p. 2). ويثير Peterlin, et al (2013, p. 206) إلى أن مفهوم القبادة المستدامة يثم بناؤه فى المؤسسات المختلفة من خلال المرور بعدد من المر احل هي: - المرحلة الاولى (الادر الك والفهم Appreciation) وتثضمن هذه المرحلة التحقق من جوهر المؤسسة وموظفيها ومن مدى عملهم بشكل جماعى، ومدى نوافر عنصر الابداع فى المنظمة وكيف ثتم إدارثه، ومدى تحفيز المنظمة لموظفيها لدفعهم نحو الابداع ونطوير مهارات القيادة المستدامة لديهم.

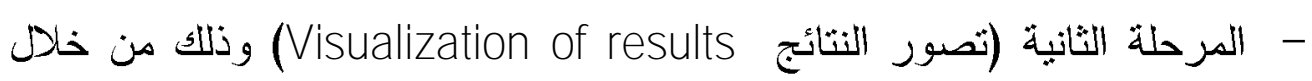
وضع وبناء تصور ورؤية مستقبلية للنتائج المطلوب من المنظمة تحقبقها مسثقبلاً من خلال التعاون بين كافة أطراف المنظمة المساهمين فى بنائها وتحقيق نتائجها. 
- المرحلة الثالثة (البناء المشترك مبري فيها الرؤية المسثقبلية إلى حيز التتفيذ من خلال تحولها إلى ممارسات فعلية لتحقيق النتائج المنشودة، وذلك من خلا الاستعانة بالوسائل المناسبة وورش العمل والتدريبات والندوات والتحليم الرسمى من أجل تتمية دهارات العمل الجماعى والمهار ات المرثبطة بالقيادة المستدامة. - المرحلة الرابعة (استدامة العمل Sustaining action) وفى هذه المرحلة ينث تمكين الأفراد فى المنظمة من ممارسة الاستدامة وتطبيقها بشكل مستمر والتعلم

$$
\text { مدى الحياة. }
$$

كما تعرف بأنها القيادة التى تعمل على تطوير المدرسة من خلال المحافظة على التعليم المستدام من خلال التكيف دع المتغيرات وتوجية المسار نحو التحسين (Bendell \& Little, 2015, p.16) المستمر

كما يعرفها حسين مجبل الرشيدى (Y. V) بأنها ثوجه معاصر فى القيادة المدرسية يمكن نطبيقة فى الييئة المدرسية يزكز على الممارسات النى من شأنها تحقيق استدامة المدارس كمؤسسات فاعلة اجنماعباً من خلال الثركيز على استدامة التعلم والنجاح، وتتمية المهارات القيادية لدى الآخرين منل المعلمين وطاقم العمل بغرض استدامة القيادة، والعمل على نشر وثوزيع القيادة ومهامها ومسئولياتها وأدوارها بين كافة أعضاء وعناصر المجنمع المدرسي، والعمل على الحفاظ على الموارد المادية والبشرية بدلا من استنزافها وتحقيق العدالة والتعلم من دروس

$$
\text { الماضى وإتباع منظور طويل الامد." (ص. } 1.0
$$

ويعرفها معهد القيادة المستدامة بأنها "قدرة أفر اد المؤسسة على اعثماد طرق جديدة للرؤية والتفكير الفاعل الذى يؤدى إلى حلول مبنكره ومستدامه، وذللك من 
خلال وعيهم بقدثهم العميقة على التغيير وعلاقتهم العميقة بالعلم من

حولهم)(Sustainable leadership Institute, 2018).

وتتير كلا من سهير محمد حوالة ، نورة بليهان المطيرى (9 ( ب ب) إلى أن

مفهوم القيادة المستدامة يعد منظوراً تربوياً يهذف إلى المحافظة على الموارد المادية و البشرية ، و التشجيع على التعلم العميق ، و المشاركة فى التخطبط مع العاملين، وارنباط المدرسة بالمجتمع المحلى، لتلبية احتباجات المتهع.(ص. ؟Vr) وتعرف أمل العردان (. Y. (Y) القيادة المستدامة بانها أسلوب قيادى للتطوير و التحسين المسنمر ونحقيق التوازن بين الاهنمام بالأقراد والموارد المالية والييئة

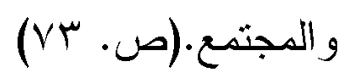

ومن خلال استعر اض التعريفاث السابقة التى نتاولت دفهوم القيادة المستدامة

ثنتخلص الباحثة أن القيادة المستدامة فى المدارس الثانوية يمكن أن ثنميز بأنها: 1. عملية تعاونبة بنترك فيها جميع أفراد المؤسسة التعليمبة بما في ذلك المدارس الثانوية بكامل طاقمها التعليمى(معلمين - متعلمين -عاملين)، فهى ثزكز على جميع عناصرها بما فى ذلك المناهج وعلمية الثعليم من أجل تحقيق التعلم العميق وتعمل على تنمية مهارات التعلم مدى الحياة. Y. تعد القبادة المستدامة فى المدارس الثانوية قبادة مرشدة ومسثثمرة، لانها تعمل على ثرشيد وحسن استغلال الموارد المادية والمعرفية وتضع فى هي حسبانها منطلبات وحاجات الاجيال القادمة.

r. تبحث دائما عن الابتكار والحلول الابتكارية للمشكلات التى توجهها ولا تفتيع بالحلول الآنية التى قد تحل المشكلة مؤقتاً ولكنها قد تخلق مشكلات أكبر فى المستفبل. 
ع. تهنم القيادة المستدامة في المدارس الثانوية على الأهداف طويلة الأمدا(رؤية

مستقبلية)، وذلك من خلال نحقيق الأهداف منوسطة وقصبرة الأمد أيضاً.

\section{خصائص القبادة المستدامة}

هناك العديد من الدراسات التى نتاولت القيادة المستدامة وأثشارات إلى بعض الخصائص لهذا النوع من القيادة ، ومن خلا مراجعة بعض الدراسات والادبيات

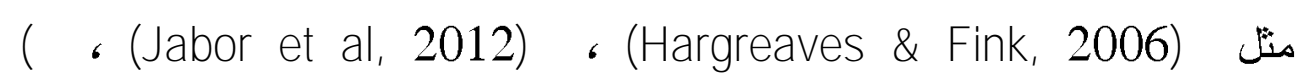
نجد أن القيادة المستخامة ثتميز بالعديد من الخصائص

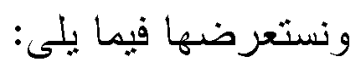
ا قيادة للتنعثم فالقيمة الأساسية للقبادة المستدامة هي القيادة للتعلم والقبادة لرعاية الآخرين وحمايتهم وتتجيعهم، والاهنمام بالعلاقات التى ثربط بينهم، وتسعى إلى تحقيق التحسين المستدام لعمليتى التعليم والتعلم.

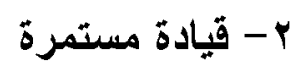

إحدى الخصائص الرئيسية للقيادة المستدامة هي أنها تتطوي على التخطيط و إعداد القادة للمراحل المُنثقبلة، من خلال قيام القائد بالاهنمام بالأفراد الناجحين و المُتميزين والذين يملكون مهارات وشخصيات القادة لإعدادهم للمرحلة المُسنقبلية، فمن الصعوبات الاساسية التى ثواجة القيادة هو تغير القادة من فترة لآخرى داخل المنظمات واختلافهم عن بعضهم البعض ولكن القبادة المستدامة تسعى التى تأكبد استمر ايتها بصرف النظر عن تغيير القائد. 


\section{ب- قيادة ترابطية وتعاونية}

القيادة المسندامة عملية ممثدة، فالقائد المستدام بحافظ على قيادة الآخرين ويعتمد عليهم في القيادة، لانه لا ثشتطيع شُركة أو مؤسسة أو قائد بمفرده أن بدير كل قضبة بدون وجود دعم من الاخرين. ع - قيادة عادلة ومسئولة اجتماعياً

القيادة المستدامة لا تشكل أي ضرر على الييئة المحيطة؛ بل تعمل على دعمها وخدمثها، كما أنها تثبع طرقًا ديناميكية لنشر الموارد والمعرفة بين العاملين بعضهم البعض، وبين المؤسسة وباقى المؤسسات الأخرى، فالقادة المهنمون بالاستدامة يتحملون مسئولية المدرسة وموظفيها، ويدركون أن أفعالهم لها نأثير على بيئنهم الخارجية. 0- قيادة رشيدة ومنتجة

تعمل القيادة المستدامة على زيادة الانتاجية بدلاً من استنزاف الموارد المالبة والبشرية، من خلال تنمية مهارات العاملين بالمؤسسة، كما أنها لا تشتتفذ قدرات قادتها فى نطبيق الافكار والاختراعات المبالغ فيها وغير العملية النى لا نؤدى إلى إحداث أى نوع من التغيير، فالقيادة المستدامة قبادة بعيدة النظر ذات رؤية مبدعة ومبتكره، كما أن القيادة المستدامة لا تهدر قدرات وموارد المدرسة بدون فائدة. צ- قيادة ذكبية وماهرة تعمل القيادة المستدامة على ثقديم المكافآت والحوافز الأساسية لموظفيها، كما ثقدم حو افز إضافية تعمل على تحفيز الأفراد أو القادة المنميزين وجذبهم للبقاء داخل المؤسسة التعليمية أطول فترة ممكنة للاستفادة من خبراتهم، كما تعمل على ثتفير الفرص لهم للتواصل فيما بينه لتبادل الخبرات فيما بينهم من ناحية ، وتوفير 
التوجيهات والمهارات والكفايات لصغار القادة الذين ينم إعدادهم لتولى القيادة فى بهى

المستقبل فى المؤسسة التعليمبة.

$$
\text { سماث القائد المستدام }
$$

يعد القائد المستدام هو المشرف على التغييرات التى تحدث داخل المؤسسة التعليمبة ولن تتحول المؤسسة إلى مؤسسة مستدامة من ثلقاء نفسها، فعلى عاثق القائد المستدام تقع مسئولية كبيرة فى إحداث ذلك التغيير، ولذلك لابد أن بمثلك العدبد من السمات والمهارات الثى ثمكنه من القيام بدوره بصورة فعالة، ولذلك نجد أن القائد المستدام يتميز بالعديد من السمات نستعرضها فيما يلى أخلاقي النزعة

بمعنى أن القائد المستدام بهنم بمصلحة الآخرين وبالمصلحة العامة وبمصلحة الحياة الانسانبة وكل أنواع الحياة الأخرى، وكذلك ثقوده اخلاقه فى جميع السلوكيات و التصرفات والقرارات التى يتخذها فى المؤسسة التى يقودها، فقد باتت أخلاقيات الإدارة من المواضيع الثي اهتمت بها المؤسسات الثربوية على اختلافها، انطلاقاً من وجوب الالتزام بالقيم الأخلاقية والقدرة على إدارة المنظمة بسلوكيات أخلاقية ، تستقي الأخلاقيات في القبادة والعمل وترجع أهميتها إلى أنها توجه قرارات الأفراد عبر مختلف المواقف، والمشكلات الثي توجدها طبيعة المهنة، ونشكل أسس وهرتكزات للعمل يعترف بها الجميع ويوافق عليها، ويتعاملون في بيئة العمل وفقاً لها (Brown \& Mitchell, 2010). وتتميز القيادة المستدامة بالثوازن بين مراعاة احتياجاث الأفراد بالمؤسسة وبين القيم الأخلاقية عند أداء كل المهام و المسئوليات المكلفين بها، وهذا يؤدى بدورة إلى استدامة الأداء المثميز داخل المؤسسة(Hardie, 2011, p. 67). 
لكى يكون الثواصل ناجح فى القيادة المستدامة لابد على القائد المستدام أن يقوم بعقد اجنماعات بشكل منتظم ومناسب للجميع، والاسنماع إلى الأشخاص الذين لا يتفقون هع المجموعة، وتشجيع أعضاء المنظمة على التعبير بصراحة عن مشاعر هم وأفكارهم، وتجنب سبطرة موظف واحد أو اثثين على سير المناقشات، Štreimikiene; ) وإثر الك أعضاء الفريث الغير مشاركين من خلال طلب رأيهم -Mikalauskiene \& Ciegis, 2020, p. 168 r- المثاركة الوجدانية (الأكاء العاطفى)

يترك القائد المستدام الجلوس فى مكتبه ويتتقل داخل المؤسسة التعليمبة ليتعرف على طاقم العمل من الموظفين والمعلمين، ليرى ويسمع ويشاهد مايقومون به ويكون على علم بكل صغيرة وكبيرة فى داخل المؤسسة ، ويكون ودودًا مع فريق العمل ، ويزى البعض أنه كلما كانت العلاقة بينه وبين المرؤوسين رسمية للغاية ، فلن يحققوا النتائج المتوقعة منهم، فقد يتعالى القائد عليهم أو يخاطبهم بلهجة قاسية تحمل بين طباتها أوامر بجب عليهم ثتفبذها دون نقاش، فالقائد لابد أن تكون لديه Štreimikiene; Mikalauskiene القدرة على فهم شعور الآخرين والاحساس بهم) . $(\&$ Ciegis, 2020, p. 167 بمعنى انه بمثلاك درجة عالية من الذكاء العاطفى (القدرة على فهم عواطفه

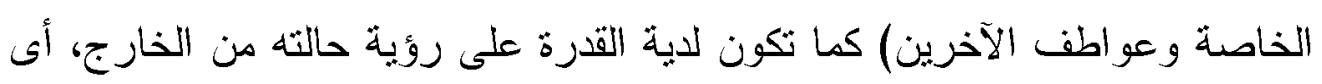
لا ثؤثز ظروف العمل ومشكلاته على حالثه المزاجية وانما بينطيع أن يؤثز فى

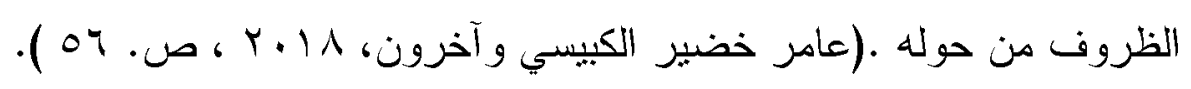




\section{؟- مشجع وملهم}

بمعنى أنه يمنح الآخرين الالهام والابتكارية والتفاؤل، ويشجعهم على القيام بأدور اهم ومهامهم وتحمل مسئولية هذه الادوار، يمناك دافعاً ذاتياً لتحقيق النتائج الإيجابية ولاية القدرة على الموازنة بين العاطفة والمثالية وبين الطموح

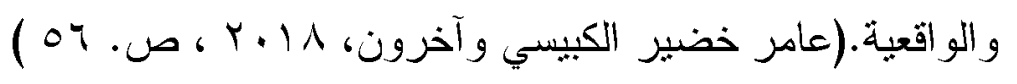

ه- الحزم و القدرة على اتخاذ القرار(الأكاء العقلاتى)

تعد القدرة على اتخاذ القرارات لايجاد حلول للمشكلات من السمات الاساسبة

للقائد المستدام حنى وإن كانت لا نثوافر المعلومات الكافية ، فقى هذه الحالة قد بعثد القائد على الحدس فى اتخاذ القرار ، أو يكون هنالك مزيجًا من التحليل العقلني و الحدس الشخصي، ويجب على القائد المستدام أن يشارك فريقه فى اتخاذ القرارات لتعليمه كيفية اتخاذ القرار من خلال منحهم القرصة لنعلم كيفية اتخاذ القرارات، مع تحديد القرارات الثي يمكن للموظفين اتخاذها بشكل مستقل، ويشرح لهم أنه بتعين عليهم تحمل المسؤولية عن قراراتهم التى بتخذونها.

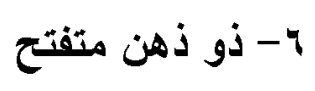

بثمنع القائد المستدام بالقدرة على البحث بجدية عن المعارف الجديد، فهو

كثير السؤال ولديه حب استطلاع ومحب لمناقشة الاراء المتباينة، ولا يستقبل المعلومات الجديدة إلا بعد التأكد منها ومن مدى مصداقيتها، كما أنه غير متعصب لر أيه فقط وانما يكون مثقبل لاث أراء أخرى حثى وان كانت تخالف ارائه الخاصة.

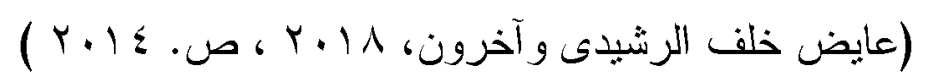


يكون القائد المستدام مثحاون مع جميع أفراد المؤسسة التعليمية من خلال مشاركته وتقييمه للمهام التى يقومون بتتفيذها وتثديم التغذية الراجعة لهم، وتقديم التحليقات الايجابية من أجل تحسين جودة العمل، فالمهام التى يقومون بها تتحسن بناء على استجابة القائد لهم و لانجاز اتهم، القائد المستدام بعمل على تثجيع المرؤوسين على إثبات أنفسهم من خلا نتفيذ المهام الموكلين بها، ويظهر لهم بانه يثق فى قدراتهم ويؤمن بأنهم سوف ينجحون فى القيام بمهامهم بصورة إيجابية.) .(Štreimikiene; Mikalauskiene \& Ciegis, 2020, p. 169 ويثفق ذلك مع ما أثـار إليه Chrisman (2005) إلى ضرورة أن تكون القيادة قائمة على التعاون والتشارك مع المعلمين مما يجعل التحسين المدرسي أكثز فاعلية ومستدام، وذلك لان مشاركة الجميع فى القيادة يؤدى إلى زيادة شعور هم بالانتماء و الالنز ام بالقرارات الثى يتخذونها.

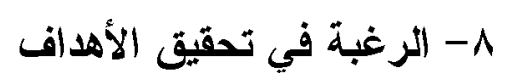

يجب أن يكون القائد المستدام مفعم بالنشاط والرغبة فى العمل من أجل تحقيق الأهداف، ولديه الاصرار على تحقيقها بصورة كاملة وعدم الاكثفاء بتحقيق جزء منها وترك الباقى. ويثير البعض إلى أن هناك بعض السمات التى يتسم بها القادة المستدامين يدركون لنقاط القوة والضعف فى مؤسساتهم وكذلك القدرات والمواهب لدى العاملين دعهم، كما أنهم منظمون لا يتصرفون بشكل عشوائى، ومقدرون لقيمة

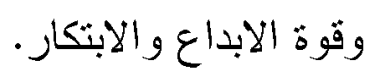


مهتمون بتقيبم أنفسه لانفسهم وثقييم الاخرين لهم، من أجل التغذية الر اجعة. بعمل القائد المستدام على إنشاء بيئة عمل و اقعية بكل عناصرها مليئة بالتحديات للحفاظ على إدارة مفعمة بالانشطة المدرسية وبناء علاقات إجتماعية هادفة داخل المؤسسة التعليمية. القيادة لدى القائد المستدام قيادة جماعية وليست فردية، قبادة تسمح بظهور عمل الآخرين وإنجاز اتهم، وتتمى قدراتهر الايجابية، فالقادة بتعاملون بشكل منظم ومترابط ومتعاون داخل المؤسسة دن أجل البقاء لأطول فترة دمكنة في قيادة المؤسسة النعليمبة.)(Skarie,2013, p. 9-11) وتزى الباحثة أن السمات السابقة مطلوبة فى القائد المستدام لانه الثخص المسئول على تطبيق الاستدامة ومبادئها في مؤسسته التعليمية، فهو أخلافى النزعة لان القيادة المستدامة تثخذ من السلوك الأخلاقي أساساً لها فى ممارساتها، ولكى يستطيع القائد المستدام تتمية موارده البشرية لابد أن يكون ذو ذهن متفتح ولديه القدرة على الاتصال و الثواصل مع مرؤوسيه للعمل على نتمية قدراتهم ومهاراتهم و إسناد المهام المناسبة لهم، ومتابعة مدى انجازهم لها وتثدير هذا الاتجاز من خلال المشاركة الوجدانية. أبعاد القيادة المستدامة تتلخص أبعاد القيادة المستدامة فى هذا البحث فى التالى: 1- التعلم العميق تهتم القبادة المستدامة بتحقيق التعلم العميق هن خلا اشراك الطلاب فى علية التعلم فكرياً وإجنماعياً وعاطفياً، وعدم النركيز على نتائج الانجاز للطلاب و اعتبار ها المحك الاساسى فى علمية التعلم، و إنما التركيز على ماور اء عملية التعلم 
مع ثقديم التغذية المستمرة للطلاب، كما أن القبادة المستدامة لا ثزكز على النتائج والمكاسب المؤقتة من عملية التعلم، بل نسعى دائما على عمل تحسينات مستدامة على عملية التعلم فى مختلف الجو انب التى يمكن قياسها (لabor, et al. 2012). ويشير Hargreaves \& Fink (2006) إلى أن القادة الذين يمارسون القيادة المستدامة بسعون إلى تحقيق التعلم العميق من خلال الاهنمام بالتعلم قبل الاهنمام بالتركيز على الامتحانات ، وجعل التعلم ذو أولوية قصوى في جميع أنشطة القبادة، وأن يكونو امتابعين لعملية التعلم فى كل مكان فى الددرسة، مع تدعيم قيادتهم بالادلة الو اضحة على سير عملية التعلم نحو تحقيق أهدافها.(p.p 41- 43) r - تنمية وتحسبن الموارد البثرية والمادية.

تعمل القبادة المستدامة على تحقيق التحسين المستدام من خلال ترشيد وتقنين استخدام الموارد المادية والبثرية، ثم ثتمية وتطوير هذه الموارد من أجل المستقبل، وتركز على تتيمة مواهب جميع العاملين فى المؤسسة التعليمية.(عائض خلف

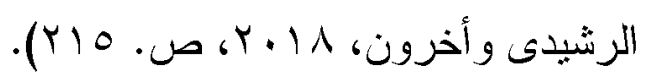

وتتيز سهير حوالة ، نوره المطيرى (9 1 +ب) إلى أن نتمية الموارد البشرية و المادية بالنسبة لقادة المدارس المستديمون تعنى أن يوفر القائد للمعلمين والطلاب

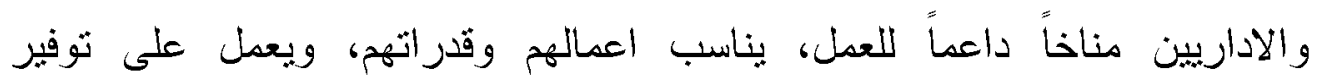
الامكانات المادية و الثقنية التى تحقق ذلك.(ص. (ص مr) وثزى الباحثة أن المحافظة على حسن استغلال الموارد البشرية والمادية من أهم المبادئ التى تسعى إليها القيادة المستدامة وذلك لضمان القدرة على الاستمرارية و التجديد. 
تثمثل إحدى الممارسات الرئيسية في المؤسسات المستدامة في اتخاذ وجهة

نظر طويلة المدى ، فهى لا نزكز على النتائج قصبرة المدى فتحقيق النوازن بين المطالب المستقبلية والمطالب قصيرة الأجل ضروري لجميع المؤسسات التعليمية؛ حيث تعثبر القيادة المستدامة نفسها مؤنمنة على رفاهية المنظمة للأجيال القادمة. (Kennedy, 2000)

ويساهم تبني منظور طويل الأمد فى تجنب مؤسسات القيادة المستدامة للتغييزات والاستراتيجيات الجديدة المفاجئة، كما بعمل على تقليل الاضطراب التى تحدث عند التعاقب الوظيفى للقادة، وذلك من خلال خطط التعاقب القائمة على الأداء طويل المدى للمؤسسة التعليمية) (Kantabutra \& Saratun, 2013, p. 360) ونرى الباحثة أن تبنى رؤية طويلة الأجل من نقاط القوى فى القيادة المستدامة، وهذه يتفق مع تعريفات القبادة المستدامة والتى تضع فى حسبانها الأجيال القادمة و احتياجاتها. ع- تبنى ورعاية الابتكار والإبداع

تعمل القيادة المستدامة على ربط احتباجات المؤسسة التعليمية بعنصر الابداع من أجل التوصل إلى حلول غير تقليدية، ويثم التعامل مع الابتكار بشكل منهجي ويثم بناء وتجميع الأفكار والمقترحات من جميع أفراد المؤسسة(Mitchell, 2001). ويؤكد ماكان وهولت McCann \& Holt (2010) على أنه من أجل نطوير أسلوب قيادة مستدام ، بحتاج القادة التظظيميون إلى أن يصبحوا ممنلين للابتكار فى مؤسساتهم ، و العمل على نطوير كفاءات معينة تعمل على بقاء المؤسسة على المدى الطويل، وتعمل على التفكير بشكل مختلف فى حل المشكلات المعقدة 
التى تتعرض لها المؤسسة التعليمبة، ومن أجل عمل تحسينات مبنكرة على الافكار

$$
\text { و الخدمات التى ثقدمها(p. 207) }
$$

$$
\text { 0- السلوك الأخلاقي }
$$

فالبعد الأخلاقي هو المرتكز الاول والرئيس فى التعاهل بين أفراد المنظمة

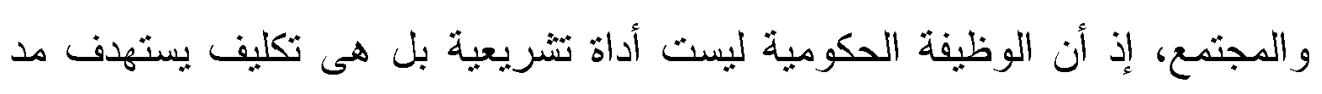
جسور التقة والتعاون بين أبناء المجثم الواحد وإدرثه بما بزيد من التزابط ويقوى المقدرة على تحقيق الأهداف.(ميسون على حسين، . . . ، ، ص. . . O) ويمكن للقائد أن بحقق السلوك الأخلاقي من خلال ممارسات السلوكبات التى التى تدعم الاستدامة مثل أن يكون نموذجاً قوياً بقندى به ، وأن بعطي رسالة واضحة بأهمية التصرف الأخلاقي، مع ثركيزة على مر اقبة العاملين ومعاقبة الذين يبتعدون عن السلوكيات الأخلاقية ، مع نوفير فرص التدريب الأخلاقي، ونوفير نظام مكافئات يعزز السلوك الأخلاقي) (Kreitner \& Kinicki, 2007, p. 41)

\section{منهج وإجراءات البحث}

منهج البحث: اعثد البحث الحالى على المنهج الوصفى الثحليلى المعثد على المسح بالاستبيان، وذللك بهدف رصد ممارسة القيادة المستدامة فى مدارس التعليم الثانوى العام بمحافظات جنوب صعيد مصر من وجهة نظر المعلمين و المديرين.

مجتمع وعينة البحث: ثمثل المجتمع الأصلى البحث فى المعلمين و المديرين بمدارس التحليم الثانوى العام الحكومية ببعض محافظات جنوب الصعيد وهى (سو هاج - قنا - الاقصر) و البالغ عددهم Yor معلم و معلمه، و I . مدير 


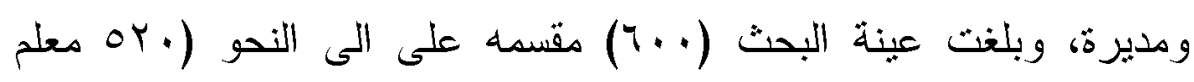

ومعلمه، و •^ مدير ومديرة ) وذلك من العدد الكلى لمجثمع الدراسة. أداة البحث: لجمع البيانات فى البحث الحالى تم بناء الاستبانة التى تحاول رصد ممارسة القبادة المستدامة فى مدارس التعليم الثانوى العام بمحافظات جنوب صعيد مصر من وجهة نظر المعلمين والمديرين، وتضمنت الاسنبانة (0) أبعاد هم (التعلم العميق - ثتمية وتحسين الموارد البثرية - ثبنى الرؤية طويلة الأكد - تبنى ورعاية الابتكار والابداع - السلوك الاخلاقى). أ- أ صدق الاستبانة

ثم التحقق من صدق الاستبانة من خلال عرضها على مجموعة من المحكمين

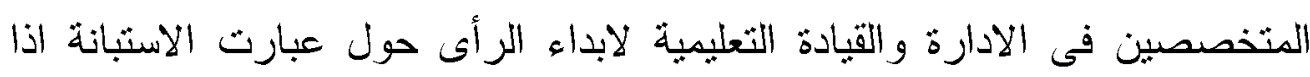

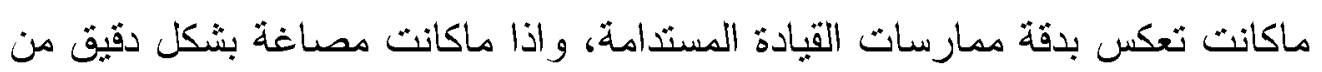

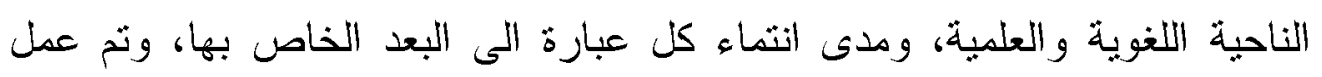
بعض التعديلات فى ضوء آراء المحكمين لتصبح الاستبانة في صورثها النهائية

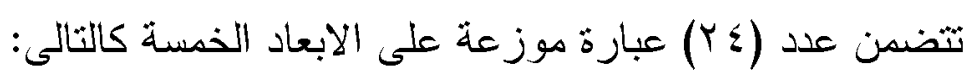

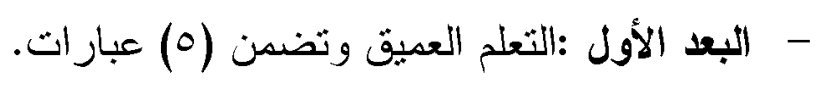
- البعد الثانى : تتمية وتحسين الموارد البشرية والمادية وتضمن (V) عبار ات. - البعد الثالث: تبنى الرؤية طويل الأكد وتضدن (ع) عبار ات. - البعد الرابع: ثبنى ورعاية الابتكار والابداع وتضمن (ع) عبار ات. - البعد الخامس: السلوك الأخلاقى وتضمن (؛) عبار ات. ب- بات الاستبانة يقصد بثبات الاسنبانة أنها ثعطى نفس النتائج إذا طبقت عدت مرات على نفس المفحوصين وتحت نفس الثروط ، ونحصل علي نفس النتائج، أو عندما ثكون 
واقع ممارسة القيادة المستدامة فى مدارس التعليم الثانوى العام بمحافظات جنوب صعيد مصر من وجهة نظر المعلمين والمديرين.

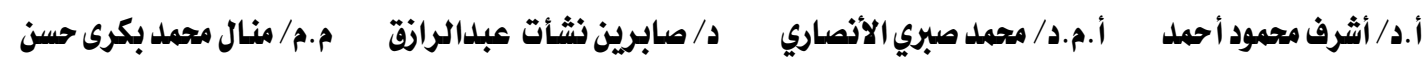

الاختلافات بينها طفيفة (ديويولد فاندلين، .199 ، ص. 115) ، وثم التحقق من

ثبات درجات الاستبانة الحالية باستخدام طريقة الاتساق الداخلى باستخدام معادلة ألفا

كرونباخ (Internal Consistency for (Alpha Cronbach) فكانت معاملات

$$
\text { الثبات كما هو موضح بالجدول التالى: }
$$

جدول (1) قيم معاملات الاتساق الداخلى لاستبانة القيادة المستدامة

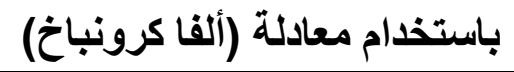

\begin{tabular}{|c|c|c|}
\hline قيم معامل الاتساق & العبارات & 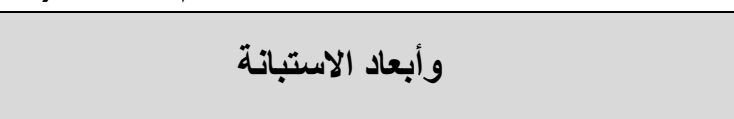 \\
\hline$\cdot . \wedge 1$ & 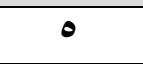 & البعد الأول :التعلم العميق \\
\hline .94 & 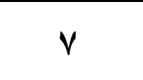 & البعد الثانى : تنمية وتحسين الموارد البشرية والمادية \\
\hline$\because V Y$ & $\varepsilon$ & البعد الثالث: تبنى الروئية طويل الأمد \\
\hline$\cdot . \wedge 9$ & $\varepsilon$ & البعد الرابع: تبنى ورعاية الابتكار والابداع \\
\hline$\cdot . \wedge$ & $\varepsilon$ & البعد الخامس: السلوك الأخلاقى \\
\hline$\cdot 97$ & $r \varepsilon$ & قيم معامل الاتساق الداخلى لمجموع أبعاد الاستبانة \\
\hline
\end{tabular}

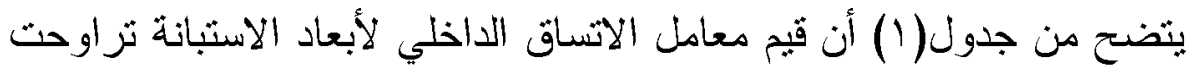

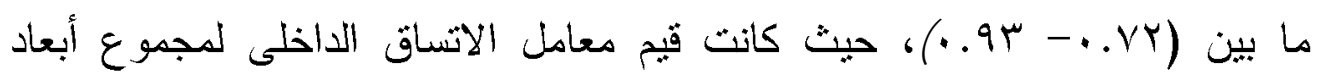
الاستبانة (T9. ·)، وجميع هذه القيم مرتفعة، مما يشبر إلي قوة ثبات الاستبانة، ودن ثم صدلاحيثها للنطبيق؛ حيث ثم تطبيقها على عينة البحث. طريقة تفريغ بيانات الاستبانة ثم تفريغ بيانات الاستبانة وفقا لييانات الجدول التالى: جدول (Y) درجة القطع لفئات الادرجات لكل مستوى من مستويات الاستجابة

\begin{tabular}{|c|c|c|c|}
\hline درجة التوافر & التقدير فى أداة الدراسة & فئات الدرجات ( المتوسط المرجح) & r \\
\hline صغيرة & يتحقق بلرجة صغيرة & من I إلى أقل من VT. & 1 \\
\hline متوسطة & يتحقق بدرجة متوسطة & 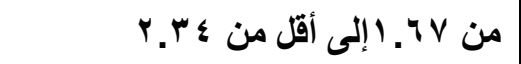 & r \\
\hline 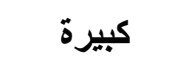 & يتحقق بلرجة كبيرة & من ع ז.ب إلى & $r$ \\
\hline
\end{tabular}


واقع ممارسة القيادة المتتدامة فى مدارس التعليم الثانوى العام بمحافظات جنوب صعيد مصر من وجهة نظر المعلمين والمديرين.

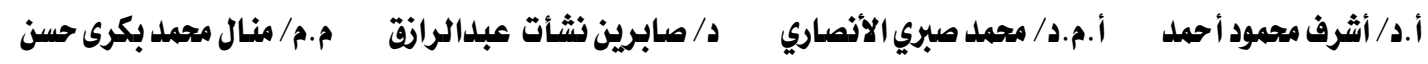

يتضح من جدول (Y) السابق ، أن درجة القطع حددت عن طريق خلايا

(1فئات) مقياس ليكرت الثلاثى المستخدم فى أداة الدراسة وفقاً لأوزان الدرجات (1)

$$
\text { r-r }
$$

نتائج البحث ومناقثتها وتفسير ها

للاجابة على نص السؤال الثانى من أسئلة البحث وهو: ما واقع ممارسة

القيادة المستدامة في مدارس التعليم الثانوى العام بمحافظات جنوب صعيد مصر من

وجهة نظر المعلمين والمديرين؟ وللاجابة على هذا السؤال تم استخراج بعض

مقاييس النزعة المركزية دن تكرارات ومتوسطاث حسابية وانحرافات معيارية

لمجموع كل بعد من أبعاد الاستبانة أداة الدراسة، ومجموع محورها الرئيسى وهو

القيادة المستدامة ودرجة نوافره بمدارس التعليم الثانوي العام بمحافظات جنوب

صعيد مصر من وجهة نظر مديرى ومعلمى مدارس التعليم الثانوي العام ،

$$
\text { وجدول(r) يوضح ذللك. }
$$

جدول (ץ) مقاييس النزعة المركزية ومقاييس التشتت للارجة توافر القيادة

المستدامة بمدارس التعليم الثانوى التعام بمحافظات جنوب صعيد مصر من وجهة

\begin{tabular}{|c|c|c|c|c|c|c|c|c|}
\hline \multirow[b]{2}{*}{ التو افر } & \multirow[b]{2}{*}{ الرتبة } & \multirow[b]{2}{*}{ الاحعراف المعيارى } & \multirow[b]{2}{*}{ المسابي } & \multicolumn{3}{|c|}{ التكر ارات } & \multirow[b]{2}{*}{ الأبعاد } & \multirow[b]{2}{*}{ المحور } \\
\hline & & & & كبيرة & متوسطة & صغيرة & & \\
\hline متوسطة & • & .r q. & 1.99 & $v \varepsilon$. & $1 \leqslant 97$ & VIE & البعد الاول: التعلم & \\
\hline متوسطة & $\varepsilon$ & טqq. & Y.. V & ITH & INOT & 1.14 & البشتبدين الموارد الثانى: تنمية & المستغامة \\
\hline
\end{tabular}

نظر المديرين والمعلمين 
واقع ممارسة القيادة المستدامة فى مدارس التعليم الثانوى العام بمحافظات جنوب صعيد مصر من وجهة نظر المعلمين والملديرين.

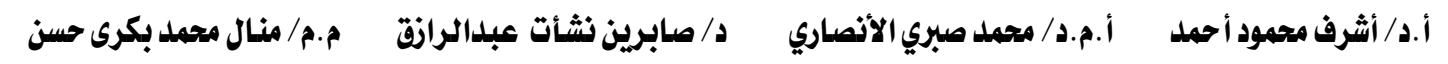

\begin{tabular}{|c|c|c|c|c|c|c|c|c|}
\hline \multirow{2}{*}{ درجة الثو أثر } & \multirow[b]{2}{*}{ الرثبة } & \multirow{2}{*}{ الالتحر اف } & \multirow{2}{*}{ |المتوسطابـ| } & \multicolumn{3}{|c|}{ التكر ارات } & \multirow[b]{2}{*}{ الأبعاد } & \multirow[b]{2}{*}{ المحور } \\
\hline & & & & درجة كبرة & درجة & صرجة صغيرة & & \\
\hline متوسطة & 1 &.$Y V V$ & Y.Y. & $V \bullet A$ & IrVq & YYr & البعد الثالث: تبنى & \\
\hline مثوسطة & Y & $.0 \vee 9$ & Y.।A & Vqr & $1 Y 09$ & $r \varepsilon q$ & ور عابة الابتكار & \\
\hline متوسطة & $r$ &.$\Delta r r$ & Y.10 & VIY & IrE. & $r \leqslant \Lambda$ & 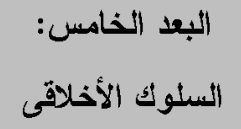 & \\
\hline منوسطة & -ー- & .571 & 1.11 & $\varepsilon H Y \varepsilon$ & VYY & YVE. & بة إمحور الثبادة & الارجة \\
\hline
\end{tabular}

يثضح من الجدول السابق(

أ- أن محور واقع القيادة المستدامة بمدارس التعليم الثانوى العام بمحافظات جنوب

صعيد مصر تكون من خمسة أبعاد وهى :( التعلم العميق، نتمية وتحسين الموارد

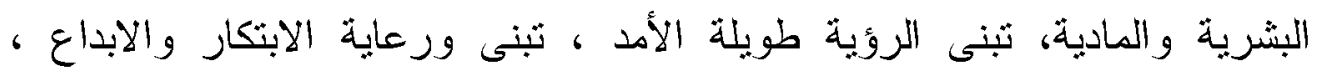
السلوك الأخلاقى) حيث جاء ثرثبب الأبعاد في استبانة واقع القيادة المستدامة بمدارس التعليم الثانوى العام بمحافظات جنوب صعيد مصر مرتب نزتيباً تتازلياً كالثالى :

• جاءت في المرتبة الأولى بُعد تبنى الرؤية طويلة الأمد بمتوسط حسابى

$$
\text { بلغ (r.Y.) }
$$

جاء في المرتبة الثانية بُعد تبنى ورعاية الابتكار والابداع بمتوسط حسابى

$$
\text { بلغ (r.). (1). (1) }
$$




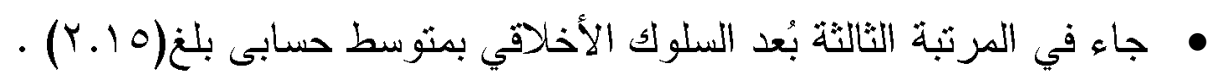
• جاء في المرتبة الرابعة بُعد نتمية وتحسين الموارد البشرية و المادية بمنوسط

$$
\text { حسابى بلغ (Y. . (Y). }
$$

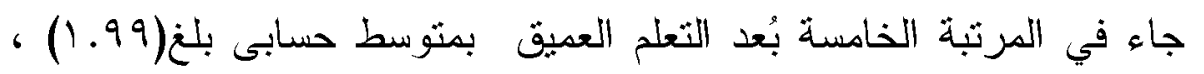
وجميع أبعاد الاستبانة حصلت على درجة ثوافر مثوسطة من وجهة نظر عينة الدراسة ، ولم يحصل أى بعد من الأبعاد الخمسة على درجة توافر

$$
\text { كبيرة أو صغيرة . }
$$

ب- أن الدرجة الكلبة لمحور القيادة المستدامة من وجهة نظر عينة الدراسة و المتمثلة في المديرين والمعلمين في مدارس التعليم الثانوى العام كانت مثوسطة إذ بلغ

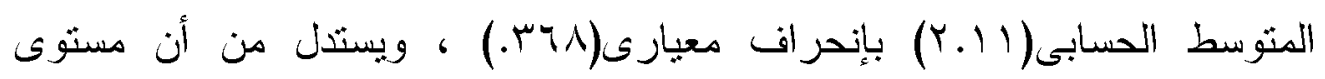
ممارسة مدخل القيادة المستدامة بمدارس التعليم الثانوى العام بمحافظات جنوب صعيد مصر محل الدراسة منوسط هو أن ما يثم نطبيقه من ممارسات القيادة المستدامة بمدارس التعليم الثانوى العام تميل أكثر إلى كونها اجتهادات وممارسات فردية أكثر من كونها سعى مؤسسى منظم وممنهج لتطبيق ممارسات القيادة المستدامة بمدارس التعليم الثانوي العام ، وتؤكد هذه النتبجة على أهية تدريب مديرى المدارس الثانوية العامة على ممارسة القيادة المستذامة ، فقد يرجع عدم تطييق مدخل القيادة المستدامة داخل المدارس الثانوية العام بشكل كبير إلى القصور المعرفى به نظراً لحداثة المدخل ومحدودية شيوع مفاهيمه، أو الرغبة في الاعتماد على الأساليب التقليدية في الأداء، و هذه النتيجة ثتفق بشكل عام مع نثائج بعض

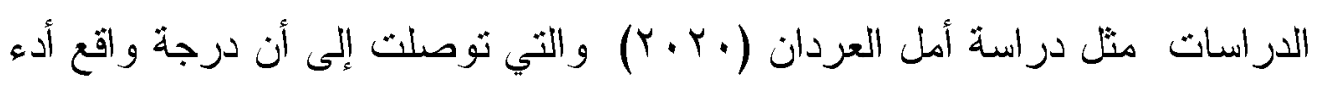
القيادة المستدامة في الجامعات السعودية الناشئة كانت منوسطة، ودر اسة سهير محد 


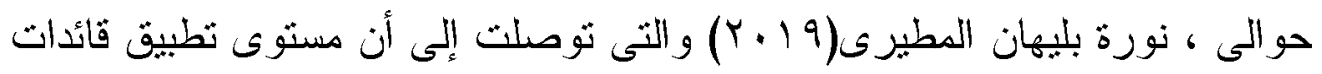
المدارس الثانوية بشمال مدينة الرياض لأبعاد القبادة المستدامة جات بدرجة

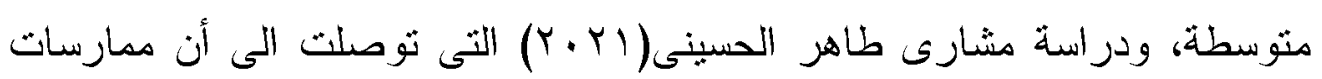
القيادة المستخامة فى مؤسسات التحليم العالى الكويتية كانت متوسطة. ثالثاً: مقترحات لتفعيل تطبيق القيادة المستدامة فى مدارس التعليم الثانوى العام بمحافظات جنوب صعيد مصر . للاجابة على السؤال الثالث فى البحث يقترح البحث بعض الثوصيات التى قد تساهم فى تفعيل نطبيق القيادة المستدامة فى هدارس التعليم الثانوى العام ومن هذه

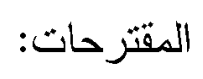

توجيه نظر مديريات التربية و التعليم والإدار ات التعليمية إلى نشر ثقافة الفكر الادارى المستدام من خلا برامج ونشرات التوعية والندوات و الدوارات و البرامج التدريبية بالتعاون مع وحدات التدريب بالمدارس ومع الاكاديمية المهنية للمعلمين بكل محافظة. توجية قادة المدارس الثانوية العامة نحو التركيز على تحسين نتائج ثعليم وتعلم الطلاب وعدم الاعتماد على نتائج الامتحانات كمحك لتقييم الطلاب و إنما التزكيز على ماور اء عملية التعلم. العمل على نشر وبناء ثقافة تنظيمية إيجايية داخل المدرسة تقوم على التعاون والروح الجماعية والعمل الفزيقى، وثرنكز على قاعدة أساسها السلوك الأخلاقى. 
واقع ممارسة القيادة المستدامة فى مدارس التعليم الثانوى العام بمحافظات جنوب صعيد مصر من وجهة نظر المعلمين والملديرين.

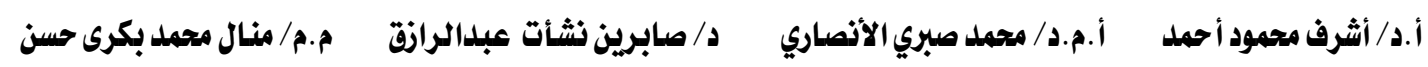

وجود رؤية ورسالة واضحة لكل مدرسة مستمدة من الرؤية العامة للسياسة التعليمبة، والاهم من ذلك فهم هذه الرؤية ومتابعة تنفيذها على المدى الطويل. وضع خطة طويلة المدى لدعم عملية الابتكار والابداع داخل المدرسة سواء من المعلمين أو الموظفين او الطلاب، لان هذا يساهم فى بناء جيل من القادة قادر على تقديم حلول ابتكارية للمشكلات التى تثعرض لها المدرسة فى

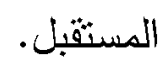
العمل على ثرشيد استهلالك الموارد المادية و البثرية ومحاولة توظيفها فى اماكنها الصحيحة، وعدم استنز افها بصورة ثهدر قيمتها و لا تعود بفائدة على

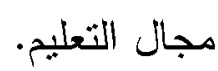
التركيز على بناء قدرة مؤسسية (أفراد - أبنية - موارد) قادرة على تنفيذ فكر الاستدامة وتطبيقها بشكل صحيح ومثابعة نطيقها فى المدارس. التمكين الادارى الذى بساهم فى مشاركة جميع الأقراد فى عملية القيادة بصورة تعود بالفائدة على العملية التعليمية، ونساهم فى بناء قدرات قيادية جديدة. تفعيل دور المشاركة المجثمية فى خدمة العملية التعليمية لثقيم الاعم الخارجى، وبصورة تجعل المدرسة تساهم بدور فعال فى خدمة اليئة

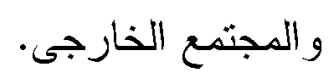




\section{المراج (2)}

أحمد نجم الدرين عبداروس.(r (r). القيادة المستدامة ودورها في تعزيز النزاهة التظظيمية بمؤسسات التعليم العام بالمملكة العربية السعودية. مجلة

$$
\text { كلية الثربية، جامعة كفز الثيخ (10) }
$$

أمال عبدالمجيد الحبلة ، سامر محمد عرقاوى. (9 (Y). القبادة المستدامة كمخل لتعزيز الابداع الثقنى فى شركات الصناعات الدوائية الفلسطينية. مجلة المثقال للعوم الاقتصادية والادرابة، جامعة العلوم الاسلامية العالمية، هـئه

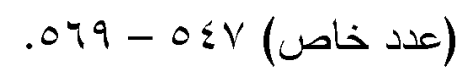

أمانى محمد يونس. (Y V IV). درجة ممارسة مديرى مدارس وكالة الغوث الدولية بمحافظات غزة للقبادة المستدامة وعلاقتها بجودة الحياة الوظيفية لدى معلميهم. [رسالة ماجسنير] ، كلية الثربية ، الجامعة الاسلامية بغزة، فلسطين.

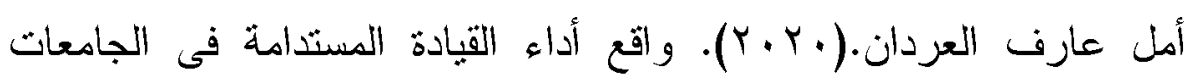
السعودية الناشئة. المجلة العربية للعلوم النتربوية والنفسية، المؤسسة العربية

$$
\text { للتريبة و العلوم والاداب، (س ())، V؟-V • 1. }
$$

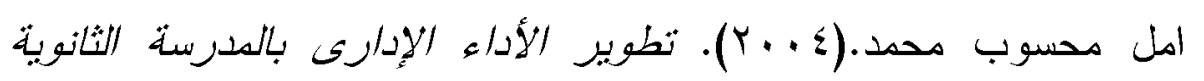
العامة فحى جهوربة مصر العربية فهى ضوء ددخل التعلبم التنظبهى . [رسالة دكتوراه] ، كلية التربية ، جامعة عين شمس.

حسين مجبل الرشيدى، العازمى مجبل. (Y V (Y). ثقييم الممارسات القيادية لدى مديري المدارس بدولة الكويت في ضوء مبادئ القيادة المستدامة. مجلة 
البحث العلمى فى الثربية، كلية البنات للاداب و العلوم و التربية، جامعة عين

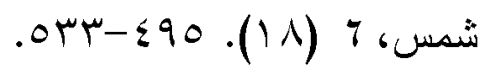

خالد خير اله، صفاء إدريس. (Y (Y). تأثير القبادة المستدامة فى تحقيق السلوك الاستباقى دراسة تحليلية لازاء عينة من تدريسي الجاهعات الأهلية العراقية. مجلة جامعة نكربت للعلوم الإدارية والاقنصادية، كلية الإدارة

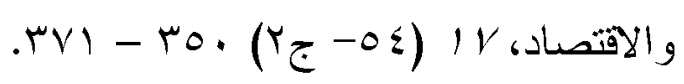

ديويولد فاندلين.(·99 (19). مناهج البحث فى التربية وعلم النفس • ترجمة (محمد نبيل نوفل و آخرون)، طء، مكتبة الأنجلو المصرية.

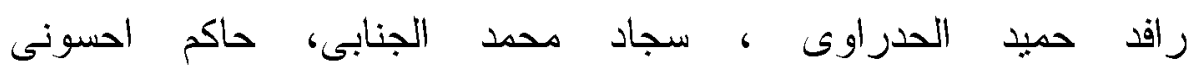

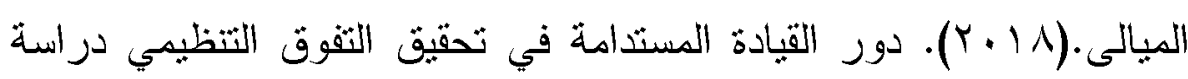
تحليلية في مطار النجف الأشرف الدولي. مجلة مركز دراسات الكوفة،

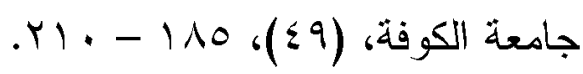
سهير محمد حوالة ، نورة بلبهان المطيرى.(9 (Y). واقع نطبيق أبعاد القيادة المستدامة لدى قائدات المدارس الثانوية الحكومية بشمال مدينة الرياض. مجلة العلوم الثربوبية، معهد الدراسات التزبوية، جامعة القاهرة،

$$
\varepsilon \cdot v-r+r(\varepsilon) r v
$$

عامر خضير الكبيسي وآخرون.(1) (Y). دراسات حول المنظمات العامة المستدامة. دار جامعة نايف للنشر . عصام جمال سليم(Y 1 (Y). و اقع ثطبيق القيادة المسندامة في جامعة مدينة السادات كمدخل لنطوير الثعليم الجامعى "هجلة مسثقبل الثربية العربية،

$$
\text { . . . - r }
$$




\section{واقع ممارسة القيادة المستدامة فى مدارس التعليم الثانوى العام بمحافظات جنوب صعيد مصر من وجهة نظر المعلمين والمديرين.}

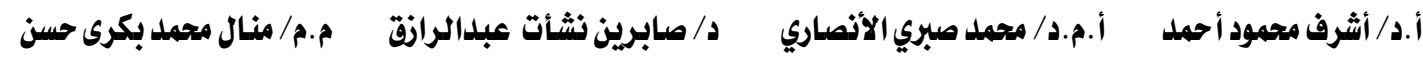

عائض خلف الرشيدى وآخرون. (1) (Y). نماذج معاصرة في القيادة. مكثبة القانون و الاقتصاد.

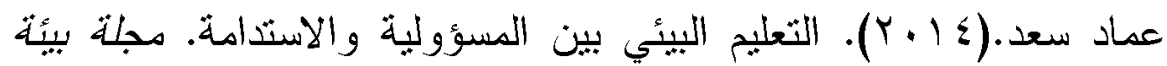

$$
\text { الدمن الإكثرونبة. (9)، ع-9 (9) }
$$

محمد عمر احمد اشتوى(YV) (Y). درجة مدارسة مدبرى النربية والنعلبم بمحافظة غزة لنمط القبادة المستد/مة وسبل تطويرها. [رسالة ماجستير]. ، كلية التربية ، الجامعة الأسلامية بغزة، فلسطين.

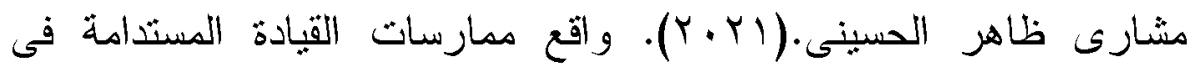
مؤسسات التعليم العالى الكويتية من وجهة نظر أعضاء هيئة التدربس. مجلة

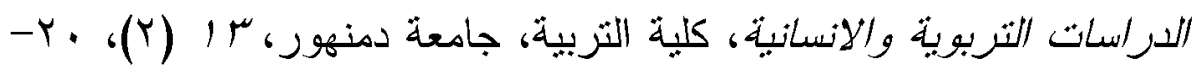
$.9 r$

ميسون على حسين. (·. . . (Y). العلاقة بين فلسفة الادارة العامة ومتطلبات التتمبة المستدامة. مجلة كلبة الادرة والاقتصاد للارلسات الاقتصادية.

$$
011-\sum 91 ،(1)
$$

- Bendell, J. \& Little, R. (2015) Seeking sustainability leadership. The journal of corporate citizenship, (60), 1326.

- Brown, M. \& Mitchell, M. (2010). Ethical and unethical leadership: exploring new avenues for future research. Business ethics quarterly, 20(4) (October), 583- 616. 
واقع ممارسة القيادة المستدامة فى مدارس التعليم الثانوى العام بمحافظات جنوب صعيد مصر من وجهة نظر المعلمين والملديرين.

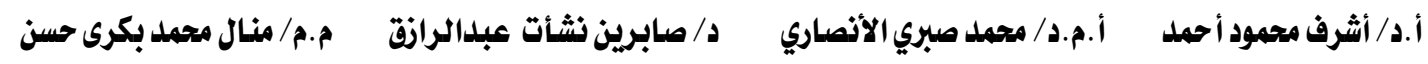

- Chrisman, V. (2005). How schools sustain success. J ournal of Educational Leadership, (62), 16- 20.

- Coyne, S. (2017). Sustainable leadership: Rewire your brain for sustainable success. Transpersonal Leadership Series: White Paper Three, Taylor \& Francis Group.

- Cook, J. W. (2014). Sustainable School Leadership: The Teachers Perspective. International J ournal of Educational Leadership Preparation, , 91), 1-17.

- Hardie, R. (2011). Principals' perceptions of the essential components of sustainable leadership and implications for succession planning at the elementary school level. [Doctoral dissertation], University of Saskatchewan, Saskatoon.

- Hargreaves, A. \& Fink, D. (2006). Sustainable Leadership. John Wiley \& Sons.

- Hargreaves, A. (2007). Sustainable leadership and development in education: Creating the future, conserving the past. European J ournal of Education, 42(2), 223-233.

- Harun, H. \& Mat K. (2014). Leadership development and sustainable leadership among Tvet student. Journal of management policies and practices. 2(2), 27- 38 . 
واقع ممارسة القيادة المستدامة فى مدارس التعليم الثانوى العام بمحافظات جنوب صعيد مصر من وجهة نظر المعلمين والملديرين.

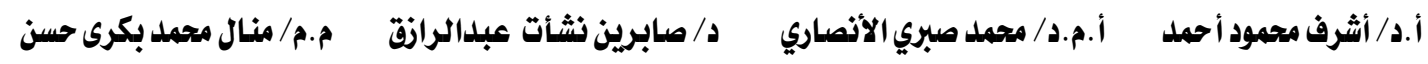

- Jabor, M.; Minghat, A.; Maigari, S. \& Buntat, Y. (2012).

Sustainable leadership for technical and vocational education and training in developing nations. International J ournal of Scientific and Research Publications, 2(8), 1- 5.

- Kantabutra, S. \& Saratun, M. (2013). Sustainable leadership: honeybee practices at Thailand's oldest university. International Journal of Educational Management. 27(4), $631-640$.

- Kennedy, A. (2000) The End of Shareholder Value: The Real Effects of the Shareholder Value Phenomenon and the Crisis it is bringing to Business. Orion Business Books, London.

- Kreithner, R. \& kinicki, A. (2007) Organizational Behavior. McGraw - Hill, $7^{\text {th }}$ ed., New York, USA.

- Mitchell, L.E. (2001). Corporate Irresponsibility: America's Newest Export, Yale University Press, New Haven, CT.

- McCann, J. \& Holt, A. (2010). Servant and sustainable leadership: An analysis in the manufacturing environment. International Journal of Management Practice, A2).134148. 
- McCann, J. \& Sweet, M. (2014).the perceptions of ethical and sustainable leadership. Journal of Business Ethics, (121), 373-383.

- Peterlin, J .; Dimovski, V. \& Penger, S. (2013). Creation of Sustainable Leadership Development: Conceptual Model Validation. J ournal of Managing Global Transitions, 11 (2), 201-216.

- Shrivastava, P., (1995). The role of corporations in achieving ecological sustainability. The Academy of Management Review, Academy of Management, 20 (4), 936- 960.

- Simanskiene, L., Zuperkiene, E., \& Pauzuoliene, J. (2016). Sustainable leadership in Lithuanian organizations. New Challenges of Economic and Business Development, society, innovations and collaborative economy: international conference. Riga, University of Latvia, 653667

- Skarie, K. (2013). Skarie, K. (2013). Sustainable Leadership: Engaging Students to Create Lasting Change on Campus. Journal of the Student Personnel Association at Indiana University, 6-14. Retrieved from 
واقع ممارسة القيادة المستدامة فى مدارس التعليم الثانوى العام بمحافظات جنوب صعيد مصر منوجهة نظر المعلمين والملديرين.

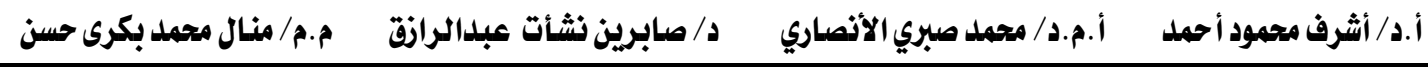

https://scholarworks. iu. edu/journals/index. php/jiuspa/article /view/3671

- $\quad$ Štreimikiene, D.; Mikalauskiene, A.; \& Ciegis, R. (2020). Sustainable Development, Leadership, and Innovations. Taylor \& Francis Group.

- Suriyankietkaew, S. (2016). Effects of sustainable leadership on customer satisfaction: Evidence from Thailand. Asia-Pacific J ournal of Business Administration, (8) 245- 259.

- Sustainable leadership Institute. (2018). Website: www. Sustainabilityleadershiplnstitute. org. (Accessed $25 / 10 / 2020)$ 